\title{
Mild bleeding disorders in adults
}

\author{
Dongmei Sun MD MSc, Chai W. Phua MD
}

Cite as: CMAJ 2021 March 8;193:E339. doi: 10.1503/cmaj.201182

\section{Patients in primary care frequently report mild bleeding that may warrant further investigation}

About $11 \%$ of patients in primary care reported bleeding symptoms in a 2010 Canadian study. ${ }^{1}$ Mild bleeding disorders should be considered in patients with disproportionate bleeding (i.e., excessive postsurgical bleeding from multiple sites or bleeding that requires blood or iron transfusion)..$^{2}$ Mild bleeding disorders can be inherited or acquired; common diagnoses include mild von Willebrand disease, platelet dysfunction and mild-moderate factor deficiencies. ${ }^{2}$ Unlike severe inherited bleeding disorders that are often diagnosed in early life, mild inherited bleeding disorders can present in adulthood.

\section{Identifying someone with mild bleeding requires a systematic approach}

First steps include a detailed medical history emphasizing bleeding and family history, a physical examination to rule out secondary conditions (e.g., Cushing syndrome or Ehlers-Danlos syndrome) (Appendix 1, available at www.cmaj.ca/ lookup/doi/10.1503/cmaj.201182/tab-related-content) and laboratory-screening tests listed in point 4. ${ }^{2}$ Recognition of an inheritance pattern could help narrow the differential diagnosis (e.g., X-linked recessive pattern in hemophilia A).

\section{3}

\section{An assessment tool may be helpful in differentiating clinically}

relevant from inconsequential bleeding

The ISTH-SSC Bleeding Assessment Tool (ISTH/SSC-BAT) may be used to differentiate the 2 types of bleeding. The tool comprises 14 distinct bleeding manifestations and takes about 20 minutes for the patient to complete (www.isth.org/page/reference tools). ${ }^{3} \mathrm{~A}$ positive score of 4 or more in males and 6 or more in females justifies referral to a specialist. However, the tool may fail to identify people with acquired bleeding disorders and is less sensitive in younger patients who have never undergone surgery.

Initial laboratory screening tests should include complete blood cell count, prothrombin time/international normalized ratio, activated partial thromboplastin time, fibrinogen level and a blood smear. If the ISTH/SSC-BAT score is negative and results for the laboratory screening tests are unremarkable, ongoing clinical observation is sufficient without further testing. ${ }^{4}$ Conversely, a positive ISTH/SSC-BAT score with normal results for laboratory tests will require referral for further evaluation.

\section{An acquired bleeding disorder may develop later in life}

Mildly disordered bleeding that arises later in life may indicate the presence of an acquired bleeding disorder, and the patient should be evaluated for underlying systemic disease. The diverse causes for an acquired bleeding disorder are listed in Appendix 1. A structured approach is necessary to ensure pathologies, such as malignant disease associated with acquired bleeding disorders, are ruled out (e.g., acquired hemophilia $\mathrm{A}$, immunoglobulin $\mathrm{M}$ hyperviscosity syndrome and lightchain amyloidosis). ${ }^{5,6}$

\section{References}

1. Bowman M, Hopman WM, Rapson D, et al. The prevalence of symptomatic von Willebrand disease in primary care practice. J Thromb Haemost 2010;8:213-6.

2. Boender J, Kruip MJHA, Leebeek FWG. A diagnostic approach to mild bleeding disorders. J Thromb Haemost 2016;14:1507-16.

3. Rodeghiero F, Tosetto A, Abshire T, et al.; ISTH/SSC joint VWF and Perinatal/Pediatric Hemostasis Subcommittees Working Group. ISTH/SSC Bleeding Assessment Tool: a standardized questionnaire and a proposal for a new bleeding score for inherited bleeding disorders. J Thromb Haemost 2010;8:2063-5.

4. Rodeghiero F, Pabinger I, Ragni M, et al. Fundamentals for a systematic approach to mild and moderate inherited bleeding disorders: an EHA consensus report. HemaSphere 2019;3:e286.

5. Menegatti M, Biguzzi E, Peyvandi F. Management of rare acquired bleeding disorders. Hematology (Am Soc Hematol Educ Program) 2019;2019:80-7.

6. Kruse-Jarres R. Acquired bleeding disorders in the elderly. Hematology (Am Soc Hematol Educ Program) 2015;2015:231-6.

Competing interests: Chai Phua has received personal fees from Hemalytic, Amgen, Gilead, Teva, Takeda/Shire, Roche, NovoNordisk, Novartis, Octapharma, Bristol Myers Squibb/Celgene, Pfizer, Bayer, Janssen, Sanofi/Bioverativ and AstraZeneca, outside the submitted work. No other competing interests were declared.

This article has been peer reviewed.

Affiliation: Department of Medicine, Schulich School of Medicine and Dentistry, Western University, London, Ont.

Content licence: This is an Open Access article distributed in accordance with the terms of the Creative Commons Attribution (CC BY-NC-ND 4.0) licence, which permits use, distribution and reproduction in any medium, provided that the original publication is properly cited, the use is noncommercial (i.e., research or educational use), and no modifications or adaptations are made. See: https://creativecommons.org/ licenses/by-nc-nd/4.0/

Correspondence to: Dongmei Sun, Dongmei.Sun@lhsc.on.ca 